\section{NUCLEAR FUSION INTRODUCED}

\section{Nuclear Fusion}

By H. R. Hulme and A. McB. Collieu. (The Wykeham Science Series for Schools and Universities.) Pp. vii +153. (Wykeham: London and Winchester, 1969.) $20 s$.

THE "Wykeham Science Series" is intended to broaden the outlook of senior grammar school pupils and to introduce undergraduates to the present state of science, but it is difficult to see how Nuclear Fusion can be recommended to grammar school pupils or even to first-year undergraduates. The introduction is confused and its level is such that real understanding is likely to be achieved only by a young reader with a wide range of background knowledge or exceptional ability. The book might perhaps be useful in a school or undergraduate library as a reference book if it were not for the total lack of references or any guide to further reading.

The mature reader with a good knowledge of physics may, however, find considerable enjoyment in the later part of the book, which deals in some detail with thermonuclear reactions in the laboratory, the problems of plasina physics, and the technological and engineering problems associated with fusion reactors. For such a reader, an attractive feature of the book is the wide range of peripheral topics which are covered. These include the evolution and abundance of the elements, cosmological theory, neutrinos and superconductivity.

\section{DAPHNE F. JACKSON}

\section{ATMOSPHERIC MOTION}

\section{Atmospheric Circulation Systems}

Their Structure and Physical Interpretation. By $\mathrm{E}$. Palmén and C. W. Newton. (International Geophysics Series, Vol. 13.) Pp. xvii +603. (Academic Press: Now York and London, July 1969.) 243s.

Is meteorology, as probably in most other rapidly advancing sciences, ideas need to be continually revised. There is so much new information that it deters even perfunctory review, while the work of digesting, clarifying and relating the gains over the whole field, for the benefit of philosophers and recruits, is perhaps passing beyond the powers and devotion of individuals. Consequently there is a dearth of good texts, and every new book published is inspected hopefully.

This book, by two authors whose contributions to the analysis of large-scale atmospheric phenomena are everywhere known and respected, has a disarming preface. "It is possible," they say, "that some readers will consider this book somewhat too qualitative or descriptive and perhaps not up to date in every respect." Well, yes, I am one of those readers, but I am grateful for the book for all that, and I commend it to others.

The atmospheric circulations which are discussed are those in the troposphere and of large scale; although attention is paid to the intense cumulonimbus, ordinary cumulus convection is represented only by transfer coefficients, and circulations of intermediate scale, such as those associated with sea breezes, are not considered. The authors choose to begin on the scale which is global, and then to reduce it, though not quite steadily. The chapters deal successively with the mean annual general circulation; its seasonal variation; air masses, fronts, jet streams and tropopauses; the polar front theory; "upper waves"; extratropical disturbances; fronts and jet streams (in more detail) and frontogenesis; three-dimensional motion in and the development of extratropical disturbances; their weather; cumulonimbus; tropical general circulation and disturbances, including hurricanes; and finally a revicw of the energetics of the various circulations.
The interposition of the discussion on fronts between those on the general circulation and the extratropical disturbances is symptomatic of a peculiar adherence to the so-called polar front "theory" (better regarded and respected as a philosophy and technique of analysis). The polar front had to be replaced by the broad baroclinic zone before a satisfactory theory of cyclones was evolved, and it is rather startling now to read of "the special importance of the polar-front theory for our present knowledge" (page vii), to find the name of Eady mentioned only once (separately from a single page given to the perturbation theory of cyclogenesis), and to read of the "general rule" that "the physical cause for the deepening of cyclones must be ultimately sought in an examination of the higher levels" (page 134). For a while, the impression grows that a cyclone is a pressure minimum on the surface weather map, although eventually (page 542) it seems "proper to consider a cyclone in the broad sense as including the neighbouring anticyclonic regions", and previously (page 338) it has been emphasized that a front is, "at least in some cases, a characteristic acquired by a cyclone during, rather than prior to, its development". Such oldfashioned attitudes are, however, usually later offset by references to recent studies, and do not affect the discussion of mean circulations and tropical disturbances.

Although the title of the book refers to physical interpretations, the relinquishment of the insight provided by perturbation theory and numerical solution of the equations of motion constrains it to detailed description without satisfactory understanding. Insistent compilation of fairly well balanced budgets of various properties, which certainly injects a backbone of quantitative and very interesting discussion into the book, is consistent with the view expressed on page 2 that the mean circulation and the disturbances "co-operate in a physically harmonious fashion to balance the energy and momentum budgets", but does not provide physical interpretation as I regard it.

Nevertheless, it would be absurd to complain that the book does not contain all one would like. It represents a great and valuable labour by the authors. It has more than 200 diagrams, of the kind one is glad to have collected together (although some suffer from the small page size), and several hundred references, work from practically all of which is sensibly incorporated into the text. It will stand as the most complete description of large-scale phenomena presented before the era of numerical analysis, satellite survey, and collaborative observational studies brought the need of surveys even more comprehensive, yet unified by physical reasoning. We will have to wait a long time before any appear, and in the meantime we can be well pleased to have the book which the authors have given us now.

F. H. LUdLam

\section{ALKALOID STRUCTURES}

\section{The Chemistry of the Isoquinoline Alkaloids}

By Tetsuji Kametani. Pp. 265. (Hirokawa: Tokyo; Elsevier: Amsterdam, London and New York, 1969.) $145 s$.

THIS book is a compilation of data and references on isoquinoline alkaloids. All of the obviously isoquinoline structural types are included as well as those, like the colchicine and Amaryllidaceae alkaloids, which are related biosynthetically. The book thoroughly covers the literature to the ond of 1967.

The tables of data are preceded by a short descriptive introduction to the field which in twenty-two pages can do no more than sketch in a very small sample of typical structural, synthetic and biosynthetic work on isoquinoline alkaloids. It is too brief to be of much value either to workers directly involved in the field or to the general reador, but would serve as a useful starting point for those newly entering on a study of this group of alkaloids. 